\title{
CYWILIZACJA MAJÓW W NOWYCH FORMACH MUZEALNYCH. O PRZYWLASZCZANIU PREKOLUMBIJSKIEGO DZIEDZICTWA NA RZECZ MEKSYKAŃSKIEJ KULTURY NARODOWEJ
}

\author{
THE MAYA CIVILIZATION IN NEW FORMS \\ OF MUSEUM EXPOSITION. APPROPRIATION \\ OF PRE-COLUMBIAN HERITAGE FOR THE BENEFIT \\ OF MEXICAN NATIONAL CULTURE
}

\begin{abstract}
The article is dedicated to the reconstruction and reinterpretation of pre-Columbian heritage by Mexican museums, with a special focus on the Maya civilization which is a permanent feature of the Mexican imagery and an object of artistic fascination. Characteristic of the history of the Yucatan, it is subject to symbolic manipulation and subordinated to the national culture. This is accompanied by the processes of its banalization, folklorization and commercialization which are facilitated by new audiovisual forms. References to the heritage are selective and the images are transformed and adjusted in order to develop apprehensible artistic products for the general public.
\end{abstract}

Key words: Mexico; the Maya; heritage; national culture; cultural appropriation; mayanization

\section{Streszczenie}

Artykuł poświęcony jest współczesnym działaniom w Meksyku w zakresie rekonstrukcji oraz reinterpretacji znaczenia spuścizny prekolumbijskiej dla kultury narodowej tego kraju, na przykładzie muzealnictwa. Chodzi zwłaszcza o dziedzi-
MAJA MAGDALENA BIERNACKA Uniwersytet w Białymstoku, Białystok E-mail: mmbiernacka@tlen.pl https://orcid.org/0000-0003-3808-8864

CITATION: Biernacka, M. M. (2019). Cywilizacja Majów w nowych formach muzealnych. O przywłaszczaniu prekolumbijskiego dziedzictwa na rzecz meksykańskiej kultury narodowej. Sprawy Narodowościowe. Seria nowa, 2019(51). https://doi.org/10.11649/sn.1819

This work was supported by the author's own resources. No competing interests have been declared.

This is an Open Access article distributed under the terms of the Creative Commons Attribution 3.0 PL License (creativecommons.org/licenses/by/3.0/pl/), which permits redistribution, commercial and non-commercial, provided that the article is properly cited. (C) The Author(s) 2019

Publisher: Institute of Slavic Studies, Polish Academy of Sciences 
ctwo Majów, które jest trwałym elementem meksykańskiego imaginarium i obiektem artystycznej fascynacji. Charakterystyczne dla historii Jukatanu i jego ludności tubylczej, podlega ono zabiegom przywłaszczania na rzecz kultury narodowej, tj. podporządkowywania jako integralnej jej części. Towarzyszą temu procesy banalizacji, folkloryzacji oraz komercjalizacji spuścizny Majów, czego przykładem są nowe formy ekspozycyjne. Odniesienia do dziedzictwa mają charakter selektywny, obrazy traktowane sa wybiórczo, adaptowane i poddawane obróbce audiowizualnej w celu wypracowania łatwych w odbiorze produktów artystycznych dla masowego odbiorcy, łączących w sposób swobodny przeszłość ze współczesnością.

Słowa kluczowe: Meksyk; Majowie; dziedzictwo; kultura narodowa; przywłaszczanie kulturowe; majanizacja

\section{WPROWADZENIE}

A rtykut dotyczy muzealnictwa w Meksyku jako środowiska, w którym konstruowane są obrazy i narracje na temat zamierzchłej przeszłości i jej znaczenia dla kultury narodowej tego kraju. Rzecz dotyczy zwłaszcza działań na rzecz uznania i współczesnych interpretacji znaczenia dziedzictwa cywilizacyjnego ludów rdzennych. Idą one w parze z zabiegami legislacyjnymi mającymi na celu uznanie praw zbiorowych i polepszenie sytuacji społeczno-demograficznej ich współcześnie żyjących potomków, polityką publiczną w tym zakresie oraz międzynarodowymi programami pomocowymi'. W tym artykule podjęte jest natomiast zadanie polegające na ukazaniu roli muzealnictwa i podejmowanych w jego ramach działań w zakresie umieszczania prekolumbijskiej spuścizny jako elementu kultury narodowej Meksyku i jej prezentowania, w tym w postaci nowych form ekspozycyjnych, zapewniających swobodę konfiguracji obrazów i reinterpretacji minionych dziejów.

Pierwszoplanowe miejsce ma w tym kontekście spuścizna Majów, która jest trwałym elementem meksykańskiego imaginarium, a współcześnie - co należy podkreślić - podlega zabiegom restytucji jako przedmiot dumy narodowej. Jest tak między innymi ze względu na jej archaiczność, a również relatywnie wysoki jak na czasy prekolumbijskie poziom tej cywilizacji, w tym pismo oraz kalendarze, a ponadto astronomię, matematykę, architekturę, sztukę oraz medycynę. Stanowi ona przedmiot zabiegów mających na celu podtrzymywanie poczucia ciągłości historycznej, podlega rekonstrukcji w pamięci zbiorowej, jest przedmiotem dumy obywateli i ma strategiczne znaczenie edukacji młodych pokoleń w duchu meksykańskiego patriotyzmu. Dziedzictwo przeszłości ma poza tym zasadniczy walor w rozwoju gospodarczym, w tym w zakresie turystyki krajowej, ale przede wszystkim międzynarodowej - szczególnie prężnej na Jukatanie oraz związanych z nią sektorów, w tym transportu, zwłaszcza lotniczego, hotelarstwa i gastronomii etc.

\section{MIĘDZY WYKLUCZENIEM SPOLECZNYM A APOTEOZA}

Choć kres cywilizacji Majów miał miejsce dawno przed ekspedycjami Hiszpanów na terytoria Nowego Świata i nastaniem epoki kolonizacji, w czasach współczesnych wciąż żyją ich potomkowie. To samo dotyczy zresztą przedstawicieli innych ludów rdzennych w re-

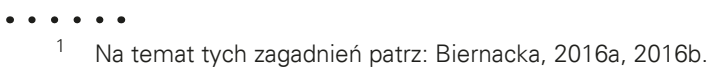

1 Na temat tych zagadnień patrz: Biernacka, 2016a, 2016b. 
gionie$^{2}$. Należy podkreślić, że przynależność do ludności rdzennej nie jest jedynie kwestią natury etnicznej ani posługiwania się prekolumbijskimi językami, które stanowią odróżniający je rys, a w większości przypadków wiąże się z niekorzystną pozycją społecznodemograficzną. W kategoriach statystycznych rdzenność stanowi w Meksyku, podobnie jak w innych krajach Ameryki Łacińskiej, jeden z wymiarów nie tylko niższej pozycji, ale też marginalizacji społecznej. Wśród ludności rdzennej wysoki jest poziom analfabetyzmu, bezrobocia oraz szereg innych problemów społecznych. Rdzenność kojarzy się w sposób niemal automatyczny z wykluczeniem społecznym, skrajną biedą i poleganiem na pomocy społecznej. Podczas gdy polityka publiczna skierowana jest przede wszystkim na działania dotyczące pragmatyki społecznej, sektor kultury, w tym muzealnictwo, bywają traktowane za pełniące rolę komplementarną w zakresie polepszenia pozycji ludów rdzennych w kategoriach symbolicznych. Jest to jednak założenie utopijne - prekolumbijscy Majowie traktowani są jako przedmiot dumy narodowej, natomiast ich potomkowie są na marginesie społeczeństwa i pozostają wykluczeni z dyskursu na temat spuścizny.

Wobec ogólnie niskiej pozycji społeczno-demograficznej ludności rdzennej, zmitologizowana przeszłość jest instrumentem pragmatycznych zabiegów podejmowanych współcześnie przez władze, organizacje pozarządowe, fundacje, muzea etc. W zakresie docenienia wagi ich dziedzictwa i współpracujących z nimi twórców - nie tylko meksykańskich, ale też zagranicznych, jak w przedstawianym dalej przykładzie nowych form muzealnych. Podczas gdy wykorzystują oni środki wyrazu, jakich dostarcza literatura, malarstwo, rzeźba czy sztuki audiowizualne na rzecz eksponowania dziedzictwa Majów, przedstawiciele rdzennych wspólnot uczestniczą w obiegu kultury przede wszystkim na poślednich pozycjach - wykonując niskopłatne prace rękodzielnicze na użytek branży turystycznej i sprzedając pamiątki na trasach wycieczek.

\section{MAJANIZACJA, CZYLI O PRZYWLASZCZANIU KULTUROWYM SPUŚCIZNY MAJÓW NA UŻYTEK MEKSYKAŃSKIEJ KULTURY NARODOWEJ}

Mimo wielowiekowego mieszania się kultur, ras i grup etnicznych, era prekolumbijska podlega symbolicznemu zagarnięciu jako nasza, to jest będąca świadectwem bogatej kulturowo przeszłości społeczeństwa Meksyku, a era kolonialna rekonstruowana jest jako będąca udziałem obcych. W ten sposób, duma jest nasza, a wstyd - cudzy, co stanowi prawidłowość dotyczącą rekonstrukcji pamięci zbiorowej o walorze uniwersalnym, to jest znajdującą odniesienie do różnych narodów, etni, ras etc. oraz podpartych nimi grup społecznych. Może wydawać się to paradoksalne zważywszy na oczywisty fakt, że mieszkańcy Meksyku są również potomkami kolonizatorów.

Poza działaniem na rzecz uznania wartości dziedzictwa Majów, ale i - jak określane jest to zjawisko w języku angielskim cultural appropriation, a w hiszpańskim - apropriación cultural, czyli zagarnięcie czy też przywłaszczenie kulturowe. W przypadku Meksyku chodzi o restytucję wartości spuścizny Majów i podporządkowanie jej jako integralnej części kultury narodowej, czemu towarzyszą procesy banalizacji, folkloryzacji oraz komercjalizacji, a zarazem odrzucanie kolonializmu jako przejawu obcej i niechlubnej ingerencji w tam-

2 Najliczniejsze wśród nich są w Meksyku plemiona Náhua, znane również w spolszczonej wersji nazwy własnej jako Nahuatlowie, na drugim miejscu pod względem liczby są plemiona Maya, czyli Majowie, dalej kolejno Zapoteco (Zapotekowie), Mixteco (Mistekowie), Otomí (Otomiowie) oraz kilkadziesiąt innych plemion. 
tejszy świat społeczny i kulturę. Gdy mowa o folkloryzacji, używam tego pojęcia w takim rozumieniu, w jakim stosuje je Józef Burszta (Burszta, 1966, ss. 39-40, 1974, s. 309)3, to jest swobodnego posługiwania się elementami kultury i zaniku autentyczności. Co więcej, selekcjonowane i wprowadzane są one do obiegu przez przedstawicieli grup dominujących w społeczeństwie, białych, a w każdym razie nie-Majów. Przez nich nadawane są też im wiążące znaczenia i interpretacje, oni też uznają je za prawdziwe i doceniają jako wartościowe - tym bardziej jako takie traktują je odbiorcy, w tym turyści, którzy są w regionie źródłem poważnych dochodów i przyczyniają się do eskalacji zainteresowania czasami prekolumbijskimi. W odniesieniu do przywłaszczania kulturowego dziedzictwa Majów, ale też innych krajach regionu, gdzie jest ono obecne, stosowane jest w literaturze przedmiotu pojęcie mayanización (hiszp. $4^{4} /$ mayanization (ang. $)^{5}$, czyli maja niza c ja. Dotyczy ono zarówno jego przywłaszczania na użytek kultury narodowej w zakresie rekonstrukcji jej historii, systemie edukacyjnym, sztukach pięknych, dyskursie politycznym, ale też w odniesieniu do partykularnych interesów aktorów społecznych, w tym np. małych, rodzinnych firm, co widoczne jest na porządku dziennym. Powszechne jest zarówno nadawanie atrybutu majańskości działaniom i obiektom, w tym przybieranie nazwy własnej tej grupy etnicznej jako miana lub elementu opisu firm, choćby biur podróży, ale też klubów nocnych czy barów, produktów i usług, np. potraw czy masaży, co tym bardziej banalizuje, fragmentaryzuje, narusza i zniekształca ich dziedzictwo.

Fakt przywłaszczenia kulturowego poddawany jest demaskacji i krytyce zarówno w odniesieniu do rekonstruowania prekolumbijskiej kultury Majów w Meksyku, jak też np. Gwatemali czy Hondurasie ${ }^{6}$. Jej elementy odkrywane są i interpretowane przez uczonych, w tym archeologów, których autorytet legitymizować ma prawdziwość przyjętych tez na temat przeszłości i pozwala tworzyć wiążącą wykładnię. Przy tym, wraz z nowymi odkryciami pojawiają się nowe dane i podważane są dotychczas obowiązujące teorie. Systematycznie wcielane są one do kultury narodowej w formie uproszczonej, fragmentarycznej, przekształcanej w produkt kultury przez artystów, personel techniczny, menedżerów kultury oraz reinterpretowane przez krytyków sztuki, kulturoznawców, edukatorów, a również odbiorców, m.in. dzięki środkom masowego przekazu i mediom społecznościowym.

\section{WIELKIE MUZEUM ŚWIATA MAJÓW JAKO WIODACA PLACÓWKA KULTURY}

Gdy mowa o branży muzealniczej i jej działaniach na rzecz rekonstrukcji i reinterpretacji spuścizny Majów jako przedmiotu dumy narodowej, kluczowe znaczenie mają następujące instytucje: 1. Gran Museo del Mundo Maya de Mérida, czyli w literalnym tłumaczeniu - choć nie brzmi ono w języku polskim fortunnie - Wielkie Muzeum Świata Majów w Meridzie, 2. Museo Maya de Cancún, czyli Muzeum Majów w Cancún oraz 3. Museo de la Cultura Maya w leżącym blisko gwatemalskiej granicy mieście Chetumal.

Warto zwłaszcza zwrócić uwagę na działalność Wielkiego Muzeum Świata Majów w Meridzie, które otwarte zostało w 2012 roku i stanowi dziś jedną z czołowych placó-

\section{......}

Patrz też: Biernacka, 2017, s. 27. W przywoływanym artykule jest mowa o przykładzie folkloryzacji w kontekście widowisk organizowanych w Hiszpanii na pamiątkę bitewnych zwycięstw chrześcijan nad Maurami podczas rekonkwisty.

4 Patrz np. Bastos \& Cumes, 2007

5 Patrz np. Joyce, 2008, s. 58. Sufiks -zation, który pojawia się w tym neologizmie, jest charakterystyczny dla amerykańskiej odmiany języka angielskiego, zgodnie z brytyjskim uzusem byłby on zastąpiony przez - sation.

6 Patrz np. Montejo, 2005; Frischmann, 2007, s. 59; Hervik, 2013, s. 59 i nast.; Maxwell, 2001, s. 196. 
wek kultury na poziomie kraju. Władze stanu Jukatan ${ }^{8}$, Narodowy Instytut Antropologii i Historii ${ }^{9}$ oraz Instytut Historii i Muzeów Jukatanu ${ }^{10}$ liczą, że placówka przynosić będzie znaczące korzyści w przyszłości, w tym m.in. w postaci zaangażowania obywateli w jej działalność, a również rozwoju turystyki kulturalnej. Jeszcze w tym samym roku, w którym inaugurowano jego działalność ${ }^{11}$, w międzynarodowym konkursie ,Partnership Awards' przyznano mu w Londynie nagrodę ,Best Pathfinder Project' w kategorii innowacyjnych projektów ochrony i popularyzacji dziedzictwa kultury (np. Walten, 2017). W roku kolejnym wręczono nagrodę Iberoamerykańskiej Rady Projektantów Wnętrz ${ }^{12}$ dla muzeum jako 'Emblematycznego Dzieła roku 2013' - uznane zostało w tym konkursie jako najlepsze na poziomie światowym w kategorii: Kultura. Podczas ceremonii, która odbyła się w mieszczącym się w nim audytorium o nazwie "Sala Mayamax" obiekt określony został jako obiekt nowatorski w skali międzynarodowej, wyróżniający się m.in. ze względu na wartość koncepcji urbanizacyjnej, emblematyczny charakter dla uniwersum Majów, ekspresyjność architektury, reprezentację w jego ramach uznanego przez Majów za święte drzewa Ceiba13, a również optymalne rozwiązania użytkowe otwartych przestrzeni, specjalistyczne rozwiązania muzeograficzne, projekty oświetleniowe i spektakli typu: światło i dźwięk, a również jakość zabudowy (np. „Otorgan al Gran Museo del Mundo Maya el Premio CIDI", 2013). Muzeum otrzymało w 2015 roku w Londynie nagrodę w międzynarodowym konkursie 'Leading Cultural Destination Awards' (np. China Xinhua Español, 2015; ExcélsiorTV Noticias, 2015; Noticias Trecevisión, 2015; „Premio a Gran Museo del Mundo Maya", 2015). Obok nadawanych wyróżnień oraz entuzjazmu, jakie budzi muzeum, pojawia się też jego krytyka, zarówno jeśli chodzi o formę architektoniczną i rozwiązania urbanizacyjne, jak i tryb sprowadzania doń eksponatów, z zastrzeżeniami dotyczącymi ich uszczerbków, a także generowanego długu publicznego wskutek podjęcia inwestycji budowy oraz bieżącego funkcjonowania placówki.

Muzeum uznaje za swój cel pozycjonowanie Meksyku oraz stanu Jukatan jako Puerta de Entrada al Mundo Maya, co oznacza: Wrota do Świata Majów, jak określone jest na stronie internetowej obiektu („Gran Museo del Mundo Maya de Mérida”, b.d.), a ponadto wzmocnienie roli miasta Merida, w którym się znajduje jako Stolicy Kultury Południowo-wschodniego Meksyku ("Gran Museo del Mundo Maya de Mérida”, b.d.) - oba określenia zapisane są z użyciem wielkich liter, co pozwala na ich silniejsze umocowanie symboliczne. Placówka przyjęła jako ogólną wizję swego działania przekazywanie uznania dla grupy etnicznej Majów jako członków żywej kultury, a zarazem dziedziców tysiącletniej spuścizny. Podejmuje działania na rzecz promowania aktywnego uczestnictwa wśród

\section{......}

Nagranie poglądowe na temat muzeum, z widoczną fasadą oraz pokazanymi ekspozycjami we wnętrzu patrz np. Pacheco, 2012.

8 Meksyk jest państwem federacyjnym z podziałem na stany (patrz Biernacka, 2016a, s. 139, przypis 15, 2016b, s. 57, przypis 15), z których jednym jest właśnie Jukatan. Mieści się on na półwyspie o tej samej nazwie, którego część przynależy poza Meksykiem do Gwatemali oraz Belize.

9 Instituto Nacional de Antropología e Historia (INAH), http://www.inah.gob.mx/es/. INAH jest podmiotem podległym władzom federalnym, mającym wiodące znaczenie na poziomie całego kraju dla działalności badawczej, ochrony dziedzictwa archeologicznego, antropologicznego i historycznego Meksyku. Ma on długą tradycję - założony został w 1939 roku za czasów prezydenta Lázaro Cárdenasa del Río na podbudowie uprzednio istniejących placówek.

10 Instituto de Historia y Museos de Yucatán (IHMY), https://www.inmy.com.mx/, Nota bene, Instytut ma swą siedzibę na terenie tego muzeum.

11 Nagranie z inauguracji placówki patrz: Cauich, 2012, nagranie z fragmentami ceremonii inauguracji placówki z 14 grudnia 2012

12 Consejo Iberoamericano de Diseñadores de Interiores (CIDI).

13 Jest to drzewo z rodziny puchowców. Jego nazwa w języku Majów to yaxche, czyli "pierwsze drzewo" (np. Christenson, 2016, s. 42; yax che'el kab' oznacza według tego autora "pierwsze drzewo świata”), ew. "pierwsze”, "nowe” lub „(niebiesko-)zielone drzewo" (por. Marcus, 1982, s. 259; Thompson, 1990, s. 195, względnie „najpierw drzewo" (np. Men, 1990, s. 57). 
mieszkańców półwyspu Jukatan, społeczeństwa meksykańskiego, a także gości międzynarodowych. Aspiracją ośrodka jest przyczynianie się do postępu społecznego, dialogu międzykulturowego, a także promocji regionu i kraju, z uwzględnieniem działań narodotwórczych w zakresie edukacji, kultury i turystyki. Misją obiektu ma być rozpowszechnianie, promocja i wzmacnianie tożsamości oraz kultury Majów poprzez programy na rzecz budowania wiedzy i uznania dla dziedzictwa Mayab - to ostatnie określenie oznacza półwysep Jukatan w języku majańskim. Powtarza się w materiałach promujących obiekt, i w istocie jest jednym z niewielu wyrazów w tym języku, które mogą być znane bądź poznane i zapamiętane przez szerszą publiczność.

Co ciekawe, jest to pierwsze muzeum w Meksyku, które uznało język rdzenny jako podstawowy dla funkcjonowania placówki. Jest nim majański z Jukatanu14, który stanowi jeden z wielu języków rdzennych w kraju. De facto, sprowadza się to jednak przed wszystkim do stwierdzenia na jego stronie internetowej jako elementu przyjętej wizji. W przeciwieństwie do języka hiszpańskiego nie jest on językiem powszechnie znanym w regionie, a tym bardziej przez odwiedzających z innych części kraju oraz gości międzynarodowych. W praktyce codziennej hiszpański pozostaje zasadniczym językiem przekazu, a uznanie majańskiego za podstawowy jest formalną deklaracją w materiałach reklamowych i stanowi pewien element wizerunkowy oraz gest na rzecz budowy godności i uznania dla ludów rdzennych, w tym szczególnie Majów, jako mających pierwszorzędne znaczenie dla kultury regionu i kraju. Ponadto, wprowadzenie go do obiegu muzealnego stworzy aurę egzotyki ze względu na jego endemiczny charakter i „prawdziwości” środowiska, w którym rekonstruowana jest majańska przeszłość.

\section{O NOWYCH FORMACH MUZEALNYCH W MUZEUM ŚWIATA MAJÓW}

Ośrodek posiada tradycyjne stałe ekspozycje oraz oferuje wystawy czasowe, gdzie wystawiane są prekolumbijskie artefakty, w tym przedmioty użytku codziennego, o znaczeniu religijnym i rytualnym, dekoracyjne, służące sztuce wojennej i in., wykonane m.in. ze złota, jadeitu i muszli, dzieła artystyczne i religijne z epoki kolonialnej, a także archiwalne dokumenty, książki i nagrania dotyczące historii regionu. Ponadto organizuje i promuje działania o charakterze performatywnym, gdzie kreowana jest rzeczywistość poprzez pokazywanie obrazów i odgrywanie scen. Placówka zapewnia też środowisko do nawiązywania interakcji, w które włączani są odwiedzający, w tym zarówno goście indywidualni, grupy oraz wycieczki szkolne. Stawiane są przed nim cele, aby był „żywą przestrzenią", o charakterze inkluzyjnym, a ponadto połączoną z otaczającą przyrodą. Odbywają się w nim spotkania łączące - jak podkreślane jest w materiałach promocyjnych na stronie internetowej - przeszłość ze współczesnością, tradycję z nowoczesnością oraz „pamięć zbiorową z kreatywnością" - to określenie samo w sobie może stanowić furtkę do swobodnych reinterpretacji przeszłości. Obiekt funkcjonuje z wykorzystaniem nowych technologii informacyjnych i systemów cyfrowych, które umożliwiają odwiedzającym „podróż w czasie i powrót do teraźniejszości", jak określane są w materiałach narracyjne i sensoryczne doświadczenia, których dostarczać mają muzealne projekty. Część interaktywnych projekcji zorganizowana jest w salas de inmersión, czyli salach immersji, jak nazywa się w branży muzealnej w języku hiszpańskim pomieszczenia, w których stosowane metody

\footnotetext{
-.....

14 Oryg. la lengua maya yucateca.
} 
audiowizualne prowadzić mają do poczucia zanurzenia się odwiedzających w doświadczeniu kultury czy świata społecznego oraz epoki czy momentu historycznego, którego dotyczy pokaz. Jako chluba muzeum traktowana jest sala Mayamax, służąca do pokazów kinowych, zarówno filmów fabularnych, jak i dokumentalnych, pełno- i krótkometrażowych, a także alternatywnych projekcji, które możliwe są dzięki zaawansowanym parametrom audiowizualnym. Wykorzystywana jest ona również do organizacji różnych wydarzeń, zwłaszcza o charakterze kulturalnym, edukacyjnym, naukowym czy popularnonaukowym w ciągu dnia, jak i po zamknięciu muzeum, w tym koncertów, recitali, wieczorów literackich i poetyckich, projekcji oper ${ }^{15}$, sztuk teatralnych, konferencji oraz sympozjów.

\section{PROJEKT YUCAMA'YA'AB, CZYLI DZIEDZICTWO MAJÓW W NOWEJ FORMIE AUDIOWIZUALNEJ}

Jeśli chodzi o nowe formy muzealne, jednym z flagowych ofert obiektu stał się projekt audiowizualny Yucama'ya'ab (Gran Museo del Mundo Maya, 2016), który sygnuje francuski artysta Xavier de Richemont. Powstał on na podstawie scenariusza dramaturga Jorge Esmy Bazána ${ }^{16}$ oraz koncepcji pisarki i poetki Beatriz Rodríguez Guillermo ${ }^{17}$. Jak podano w broszurze reklamującej Yucama'ya'ab (El Gran Museo del Mundo Maya de Mérida, Espectáculo de luz y sonido del artista francés Xavier de Richemont, b.d.), nazwa projektu powstała z wykorzystaniem wyrazów w języku hiszpańskim i majańskim, aby stanowić reprezentację niegdysiejszej i dzisiejszej krainy Majów na Jukatanie w wymiarze kulturowym oraz geograficznym. Ma ona zarazem odzwierciedlać scalenie różnych elementów, w tym idei, muzyki i brzmienia. Projekt podzielony na pięć aktów ${ }^{18}$ podzielonych na 34 sekwencje animowanych obrazów, na które składają się rysunki, fotografie, kompozycje graficzne oraz dokumenty ikonograficzne, dla których wspólnym mianownikiem jest inspiracja światem Majów. Choć w założeniu spektakl ma stanowić chronologiczne uporządkowaną historię, tworzy on bardziej środowisko sensoryczne niż narracyjne. Nie jest on źródłem systematycznych danych faktograficznych, stanowiących systematyzację ani też analizę dziejów Majów.

W przeciwieństwie do tradycyjnego kontaktu z eksponatami, opartego na ich kontemplowaniu czy studiowaniu, uczestnictwo w spektaklu nie wymaga od odbiorców wysokich kompetencji symbolicznych. Ma charakter inkluzyjny, zapewniając przede wszystkim doświadczenia zmysłowe związane ze współgraniem form plastycznych i brzmienia oraz ich dynamiką z wykorzystaniem efektów, jakie umożliwiają współczesne technologie, w tym laserowe. Ich wykorzystanie pozwala na stworzenie nowej ramy dla ekspozycji m.in. zdjęć eksponatów oraz dokumentów. Przybierają one postać szybko zmieniających się obrazów, podobnie jak w teledyskach. Fakt, że wpisane są one w bryłę budynku, kraj-

15 Przykładem są reklamowane w okresie pisania przeze mnie artykułu projekcje wideo Requiem oraz Aídy na podstawie Giuseppe Verdiego. Program aktualnych wydarzeń organizowanych przez placówkę: „Gran Museo del Mundo Maya: Actividades y Eventos", 2017.

16 Pełni on zarazem funkcję dyrektora Instytutu Historii i Muzeów Jukatanu oraz Międzynarodowego Festiwalu Kultury Majów o akronimie FIC-Maya.

17 Do swej śmierci w 2016 roku była dyrektorem Escuela Superior de las Artes de Yucatán (ESAY), czyli Wyższej Szkoły Sztuk Jukatanu. Znana jest zwłaszcza dzięki swym pracom literackim i poezji dla dzieci.

18 Akt 1: Wyłonito się z morza (Surgió del mar), Akt 2: Majowie przedhiszpańscy (Los mayas prehispánicos), Akt 3: Konkwista i opór (La conquista y la resistencia), Akt 4: Gospodarstwa uprawiające agawę henekwen \{jest to gatunek agawy uprawiany m.in. w Meksyku\} (Las haciendas henequeneras), Akt 5: Odzyskać nasze słowo. Poetyka dzisiejszych Majów. Legendy (Recuperar nuestra palabra. Poética de los mayas de hoy. Leyendas). Tłum. M.B. 
obraz i otoczenie społeczne, jakie tworzą uczestnicy spektaklu, nadaje im dodatkowo waloru zwanego auratycznością ${ }^{19}$. Dzieło ma aurę, tj. jak uznaje posługujący się tym pojęciem Walter Benjamin - wiąże się z wizualnym odbiorem, który zapewnia spoiwo dla kontemplacyjnego utożsamiania się, integracji i budowania wrażenia wspólnoty (Koepnick, 1999, s. 110). Lutz Peter Koepnick (Koepnick, 1999, s. 110) zauważa, że doświadczenia auratyczne wiążą się z artykulacją więzów między cywilizacją a naturą oraz tym, co ożywione i nieożywione. Ponadto, dzieło „nicuje przestrzeń”, jak określa Piotr Schollenberger (Schollenberger, 2014) za historykiem sztuki Georgem Didi-Hubermanem, który stosował to określenie w opisie prac, które tworzy artysta Giuseppe Penone. Tym bardziej, gdy mowa o spektaklu, jego dynamika oraz gra wrażeniem przybliżania się i oddalania wyświetlanych obrazów pozwala osiągnąć efekt ciągłej zmiany dystansu.

Spektaklowi towarzyszy muzyka, będąca jego integralną częścią, a wykorzystująca zarówno tradycyjne brzmienia charakterystyczne, popularne piosenki meksykańską, jak i muzykę klasyczną, których połączenie zwiększa dramaturgię wyrazu. Projekcje Yucama'ya'ab zaplanowane zostały jako okresowe, wyświetlane wieczorami pod koniec tygodnia. Wyświetlane są one na elewacji obiektu oraz na podświetlonym tle konarów Ceiby i uczestnictwo w nich jest bezpłatne. Spektakl można oglądać z tarasów, bulwarów oraz ścieżek dla pieszych wokół obiektu. Fakt ten, obok braku bariery jeśli chodzi o kompetencje symboliczne odbiorców przyczynia się do tego, że jest on bardziej inkluzyjny. Sprawia ponadto, że spektakl staje się medium do kontaktów międzyludzkich i ogniskuje je, a teren obiektu stawać może się miejscem spotkań.

\section{ZAKOŃCZENIE}

Dziedzictwo Majów jest ważnym przedmiotem praktyk artystycznych oraz trzonem funkcjonowania licznych podmiotów, wśród których szczególną rolę odgrywają meksykańskie muzea. W kategoriach ideowych, i to zarówno na poziomie oddolnym, jak i owych odgórnych procesów, działaniom tym przyświeca sens - w Weberowskim (Weber, 1922/2002) rozumieniu, że istnieje konieczność kompensaty krzywd ludności rdzennej, które miaty miejsce w epoce kolonialnej. Niezależnie, czy konceptualizowany jest w kategoriach moralnych czy pragmatycznych, w tym politycznych i biznesowych, kanalizuje on prace szeregu instytucji w zakresie pozycji ludów rdzennych w społeczeństwie Meksyku. Wokół tego celu zogniskowana jest polityka społeczna i programy pomocowe. W przypadku muzealnictwa nie są wprawdzie przedmiotem działań kwestie społeczno-demograficzne dotyczące ludów rdzennych, ale ich umiejscowienie symboliczne. Chodzi nie tylko o to, że ich spuściźnie nadawane jest kluczowe znaczenie dla kraju i regionu, ale ma miejsce zagarnianie go na użytek kultury narodowej.

Nie jest oczywiście tak, aby pochylanie się nad finezją osiągnięć Majów było powszechną praktyką życia codziennego. Prawdziwe ich docenianie jest rysem nielicznych, natomiast obiektem powszechnego zainteresowania jest przede wszystkim to, co łatwe w odbiorze, służące dziś jako wdzięczny przedmiot obrazowania oraz estetyzacji.

19 Tj. dzieło czy też obiekt komunikuje się z otoczeniem, jednak jest to - jak określa Theodor W. Adorno - proces non-significative, czyli bez nadawania znaczeń (Sherratt, 2004, s. 178 i nast.). 
Bastos, S., \& Cumes, A. (Red.). (2007). Mayanización y vida cotidiana: La ideología multicultural en la sociedad guatemalteca (T. 2). [b.m.]: FLACSO/ Cirma/ Cholsamay/Centro de Investigaciones Regionales de Mesoamérica.

Biernacka, M. (2016a). Idealizm programów rozwoju a realia społeczno-demograficzne: marginalizacja rdzennej ludności w Meksyku. W K. Jarecka-Stępień \& A. Surdej (Red.), Tożsamość i efektywność: W poszukiwaniu mechanizmów zrównoważonego rozwoju (ss. 129-151). Toruń: Wydawnictwo Adam Marszatek.

Biernacka, M. (2016b). Między konfliktem a pojednaniem: Ludy rdzenne Meksyku w ustawie zasadniczej i działalności administracji publicznej. Polityka i Społeczeństwo, 2016(4(14)), 52-68.

Biernacka, M. (2017). Moros y Cristianos, czyli o konfrontacji między islamem a chrześcijaństwem w kulturze Hiszpanii. Sensus Historiae, 26, 23-33.

Burszta, J. (1966). Folklor, folklorystyka, folkloryzacja. Teatr Ludowy, 1966(1-2).

Burszta, J. (1974). Kultura ludowa - kultura narodowa: Szkice i rozprawy. Warszawa: Ludowa Spółdzielnia Wydawnicza.

Cauich, C. (2012, grudzień 14). Gran Museo del Mundo Maya [Video]. Pobrano 16 listopada 2017, z https://www.youtube.com/watch?v=CUjNoM7Wrtw

China Xinhua Español. (2015, październik 18). Museo del Mundo Maya obtiene reconocimiento como "Mejor Destino Cultural Emergente" [Video]. Pobrano 13 listopada 2017, z https://www.youtube.com/watch?v=-xbtHlu0w60

Christenson, A. J. (2016). The burden of the ancients: Maya ceremonies of world renewal from the Pre-Columbian Period to the Present. Austin: University of Texas Press.

El Gran Museo del Mundo Maya de Mérida, Espectáculo de luz y sonido del artista francés Xavier de Richemont. (b.d.). [Broszura reklamowa]. Pobrano 14 listopada 2017, z https://www.granmuseodelmundomaya.com.mx/assets/files/museo/folletos/luz_sonido.pdf

ExcélsiorTV Noticias. (2015, październik 13). Museo del Mundo Maya reconocido en Londres como uno de los mejores de su tipo/Nacional [Video]. Pobrano 16 listopada 2017, z https://www.youtube.com/watch?v=nggBexyVu2l

Frischmann, D. (2007). Buscando el equilibrio: Teatro indígena en la conjunción de milenios. W C. Montemayor \& D. Frischmann (Red.), Words of the true peoples/Palabras de los Seres Verdaderos: Anthology of contemporary Mexican indigenous-language writers: T. 3. Theatre/Teatro (ss. 48-77). Austin: University of Texas Press.

Gran Museo del Mundo Maya de Mérida. (b.d.). Pobrano 9 listopada 2017, z https://www. granmuseodelmundomaya.com. $\mathrm{mx} / \mathrm{museo}$

Gran Museo del Mundo Maya. (2016, sierpień 31). Yucama'ya'ab [Video]. Pobrano 12 listopada 2017, z https://www.youtube.com/watch?v=17qxgnsfVcl

Gran Museo del Mundo Maya: Actividades y Eventos. (2017). Pobrano 15 listopada 2017, z https://www.granmuseodelmundomaya.com.mx/planea-tu-visita/actividades-y-eventos/

Hervik, P. (2013). Mayan people within and beyond boundaries: Social categories and lived identity in Yucatán. Abingdon: Routledge. https://doi.org/10.4324/9780203954768

Instituto de Historia y Museos de Yucatán (IHMY). (b.d.). Pobrano 13 listopada 2017, z https://www.ihmy.com.mx/ 
Instituto Nacional de Antropología e Historia (INAH). (b.d.). Pobrano 13 listopada 2017, z http://www.inah.gob.mx/es/

Joyce, R. A. (2008). Critical histories of archeological practice. W J. Habu, C. Fawcett, \& J. M. Matsunaga (Red.), Evaluating multiple narratives: Beyond nationalist, colonialist, imperialist archeologies (ss. 56-68). New York, NY: Springer.

Koepnick, L. P. (1999). Walter Benjamin and the aesthetics of power. Lincoln: University of Nebraska Press.

Marcus, J. (1982). The plant world of the sixteenth- and seventeenth century Lowland Maya. W K. V. Flannery (Red.), Maya subsistence: Studies in memory of Dennis E. Puleston (ss. 239-274). London: Academic Press Inc.

Maxwell, J. M. (2001). Prescriptive grammar and Kaqchikel revitalization. W E. F. Fischer \& R. McKenna Brown (Red.), Maya cultural activism in Guatemala (ss. 195-207). Austin: University of Texas Press.

Men, H. (1990). Secrets of Mayan science/religion. Santa Fe, NM: Bear and Company Publishing.

Montejo, V. D. (2005). Maya intellectual renaissance: Identity, representation, and leadership. Austin: University of Texas Press.

Noticias Trecevisión. (2015, październik 2). El Gran Museo del Mundo Maya de Mérida de los mejores [Video]. Pobrano 15 listopada 2017, z https://www.youtube.com/ watch?v=TRieduijpRO

Otorgan al Gran Museo del Mundo Maya el Premio CIDI. (2013, marzec 20). Pobrano 12 listopada 2017, z https://arteyculturaenrebeldia.com/2013/03/20/otorgan-al-granmuseo-del-mundo-maya-el-premio-cidi/

Pacheco, R. (2012, lipiec 18). Recorrido virtual del Gran Museo del Mundo Maya. Pobrano 10 listopada 2017, z https://www.youtube.com/watch?v=2vG5xkQzCqk

Premio a Gran Museo del Mundo Maya. (2015, październik 15). Rumbo Nuevo: El Diario de la Vida Tabasqueña. Pobrano 12 listopada 2017, z http://www.rumbonuevo.com. mx/premio-a-gran-museo-del-mundo-maya/

Schollenberger, P. (2014). Odosobnienie: Próby dekonstrukcji krajobrazu. Widok: Teorie i praktyki kultury wizualnej, 2014(8).

Sherratt, Y. (2004). Adorno's positive dialectic. Cambridge: Cambridge University Press.

Thompson, J. E. S. (1990). Maya history and religion. Norman: University of Oklahoma Press.

Walten, K. (2017, czerwiec 12). The Great Museum of the Mayan World - Merida. Pobrano 11 listopada 2017, z https://www.locogringo.com/the-great-museum-of-the-mayanworld-merida/

Weber, M. (2002). Gospodarka i społeczeństwo: Zarys socjologii rozumiejącej (D. Lachowska, Tłum.). Warszawa: Wydawnictwo Naukowe PWN. (Oryg. wyd. 1922). 